\title{
Persepsi Wisatawan Terhadap Kawasan Suci Pura Masceti Di Desa Medahan Kecamatan Blahbatuh Kabupaten Gianyar
}

Gede Surya Arta Darma a, 1, I Putu Anom a, 2

${ }^{1}$ suryaartadarma@gmail.com, 2 putuanom@unud.ac.id

a Program Studi S1 Destinasi Pariwisata, Fakultas Pariwisata,Universitas Udayana, Jl. Dr. R. Goris, Denpasar, Bali 80232 Indonesia

\begin{abstract}
The Sacred area of Masceti Temple is located in Medahan Village, Blahbatuh District. The Number of tourists began increasing is an indication of the tourism potential that can be developed. This is the background of choosing the topic "Tourist Perception of Masceti Temple Sacred Area in Medahan Village" to be studied.

This research used qualitative and quantitative study methods those are qualitative descriptive analysis, validity test analysis, reliability test and frequency analysis to know the perception of tourists to the destination. Data sources from primary data and secondary data. Data completion technique using observation method, interview, literature study, documentation, and questionnaire. The technique of determining tourist samples used in this study is a quota sampling technique.
\end{abstract}

The finding of Tourism Potentials are panoramic nature, socio-cultural, artificial or economical and the perception of tourists to destination consist into four aspects those are tourist perception of tourism attraction, tourist perception of access to location, tourists perception of tourism facility and tourist perception of tourism service.

From this research can be concluded that The Sacred Area of Masceti Temple already has tourism potentials which is needed for a way for the development that must follow the rules of The Sacred Area of Masceti Temple. So, it can be realized without reducing the sanctity of Masceti Temple as Kahyangan Jagat Temple in Gianyar regency, Bali.

Keywords: Tourism Potential, The Sacred Area of Masceti Temple, Medahan Village

\section{PENDAHULUAN}

Bali yang memiliki sejumlah keunikan di setiap daerah tujuan wisata terus melakukan upaya pengembangan potensi wisata. Upaya pengembangan yang dilakukan setiap daerah bervariatif dan berpengaruh terhadap kunjungan wisatawan ke daerah tersebut.

Kabupaten Gianyar memiliki kunjungan wisatawan baik mancanegara maupun nusantara mencapai angka 1.921 .819 orang, Disparda Bali (2014). Kabupaten Gianyar memiliki sejumlah destinasi unggulan yang dapat menarik wisatawan untuk berkunjung.

Pulau Bali yang dijuluki sebagai Pulau Dewata atau Pulau Seribu Pura merupakan julukan yang diberikan wisatawan terhadap Pulau Bali. Pulau Bali memiliki kesucian yang sepatutnya dijaga bersama oleh masyarakat Bali. Kesucian di Pulau Bali identik dengan adanya Pura di berbagai penjuru.

Pura merupakan tempat suci bagi umat Hindu yang bermakna sebagai suatu tempat yang memiliki kesakralan bagi umat Hindu dan tempat persembahyangan memuja Ida Sang Hyang Widi Wasa berserta manifestasinya.

Pura yang berstatus Pura Kahyangan Jagat yang berada di Kabupaten Gianyar adalah Pura Masceti berlokasi di Desa Medahan. Terdapat aktivitas kunjungan wisatawan yang mulai meningkat di Kawasan Suci Pura Masceti, khususnya saat sore hari yang sering dimanfaatkan kelompok tertentu untuk kegiatan yoga ataupun hanya sekedar melihat pemandangan Pantai Masceti. Dilihat dari kunjungan wisatawan tersebut, Kawasan Suci Pura Masceti memiliki potensi-potensi wisata yang dapat diidentifikasi untuk pengembangan daerah tersebut. Penelitian ini bertujuan untuk mengidentifikasi potensi-potensi wisata serta aspek penunjang yang ada melalui persepsi wisatawan yang berkunjung ke Kawasan Suci Pura Masceti.

\section{KEPUSTAKAAN}


Berikut adalah landasan konsep dan teori yang digunakan dalam penelitian ini :

1. Konsep Potensi Wisat (Sujali, 1989)

2. Konsep 4A (Ariyanto, 2005)

3. Konsep Wisatawan (Undang-undang nomor 10 tahun 2009)

4. Teori Persepsi (Robbins (2003)

\section{METODE PENELITIAN}

Penelitian ini dilakukan di Kawasan Suci Pura Masceti yang terletak di Desa Medahan Kecamatan Blahbatuh yang merupakan salah satu tempat yang memiliki potensi wisata di Kabupaten Gianyar. Pemilihan lokasi Kawasan Suci Pura Masceti yang diangkat sebagai penelitian kali dipertimbangkan melalui beberapa hal seperti status Pura ini yang merupakan salah satu Pura Kahyangan Jagat.
Penelitian ini menggunakan variable Potensi Wisata yang terdapat di Kawasan Suci Pura Masceti dan Persepsi Wisatawan Terhadap Kawasan Suci Pura Masceti di Desa Keramas Kecamatan Blahbatuh, sebagai berikut

1. potensi wisata yang bersifat alami

2. potensi yang bersifat sosial dan kebudayaaan

3. potensi wisata yang bersifat buatan

Variabel persepsi wisatawan terhadap Kawasan Suci Pura Masceti yaitu :

1. Persepsi Wisatawan terhadap Atraksi Wisata

2. Persepsi Wisatawan terhadap Akses Menuju Lokasi

3. Persepsi Wisatawan terhadap Sarana Pariwisata

4. Persepsi Wisatawan terhadap Kualitas Pelayanan

Tabel 3.1 Variabel dan Indikator Persepsi Wisatawan

\begin{tabular}{|c|c|c|}
\hline No & Variabel & Indikator \\
\hline 1. & $\begin{array}{l}\text { Atraksi Wisata } \\
\text { (X.1) }\end{array}$ & $\begin{array}{l}\text { 1. Keindahan alam pantai masceti } \\
\text { 2. Museum Subak sebagai tempat wisata baru di kawasan } \\
\text { 3. Arsitektur Pura Masceti }\end{array}$ \\
\hline 2. & $\begin{array}{l}\text { Akses Menuju Lokasi } \\
\text { (X.2) }\end{array}$ & $\begin{array}{l}\text { 1. Jarak Tempuh dengan destinasi yang lain dan pusat kota } \\
\text { 2. Kualitas jalan menuju lokasi }\end{array}$ \\
\hline 3. & $\begin{array}{l}\text { Sarana Pariwisata } \\
\text { (X.3) }\end{array}$ & $\begin{array}{l}\text { 1. Penginapan yang dekat dengan lokasi } \\
\text { 2. Fasilitas Umum seperti warung, tempat parkir dan toilet } \\
\text { 3. Fasilitas memadai sebagai destinasi }\end{array}$ \\
\hline 4. & $\begin{array}{l}\text { Kualitas Pelayanan } \\
\text { (Y) }\end{array}$ & $\begin{array}{l}\text { 1. Kebersihan di lokasi kawasan } \\
\text { 2. Lahan parkir yang memadai } \\
\text { 3. Kemanan dan kenyamanan wisatawan } \\
\text { 4. Kesan positif kunjungan wisatawan }\end{array}$ \\
\hline
\end{tabular}

Sumber : Hasil modifikasi peneliti menurut Konsep 4A Ariyanto (2005)

Jenis Data yang digunakan adalah data kualitatif dan data kuantitatif. Data Kualitatif mengenai Gambaran Umum Pura Masceti, Sejarah dan Potensi - potensi Wisata Kawasan Suci Pura Masceti serta sarana pariwisata penunjang potensi wisata di Kawasan Suci tersebut. Sedangkan Data Kuantitatif mengenai kuesioner persepsi responden terhadap keberadaan potensi wisata serta aspek penunjang pariwisata di Kawasan Suci Pura Masceti di Desa Medahan, Arikunto (2002).
Berdasarkan sumbernya, data yang digunakan dalam penelitian ini dibedakan menjadi dua antara lain sebagai berikut data primer dan data sekunder. Teknik pengumpulan data dalam penelitian ini adalah Observasi, Wawancara, Dokumentasi, Studi Pustaka dan Kuesioner. Dengan Skala Likert, maka variabel yang akan diukur dijabarkan menjadi indicator variabel yang dibagi menjadi 5 (lima) skala. 
Teknik penentuan informan Purposive adalah (Budiyono, 2003). Kriteria ini harus sesuai dengan topik penelitian sebagai berikut :

1. Ketua Panitia Subak Pengempon Pura Masceti

2. Pengelola Kawasan Jaba Sisi Pura Masceti

3. Jero Mangku Pura Masceti

Teknik pengambilan sampel dalam penelitian ini merupakan Teknik Quota Sampling (Martono, 2010). Dalam penelitian kali ini jumlah kuesioner yang akan disebarkan adalah 30 kuesioner yang dibagi menjadi dua kelompok yaitu :

1. Wisatawan Mancanegara (15 kuesioner )

\section{Wisatawan Domestik (15 kuesioner} )

Teknik Analisis data (Sugiyono, 2009), Penelitian ini digunakan teknik analisis deskriptif kualitatif dan Uji kueisioner.

\section{IV.HASIL DAN PEMBAHASAN}

Pura Masceti terletak di pinggir Pantai Masceti, Desa Medahan - Keramas. Pada tahun 1995, sebelum diadakannya pemekaran desa di bulan februari Desa Medahan menjadi bagian dari Keramas. Namun saat ini, Medahan dan Keramas memiliki otonomi yang sama, baik secara kedinasan maupun adat. Namun tetap berada di wilayah teritorial Kecamatan Blahbatuh, Kabupaten Gianyar.

Pura Masceti yang berlokasi di wilayah subak ceti relatif mudah untuk dicari, melalui jalan Prof. Dr. Ida Bagus Mantra diperempatan petunjuk jalan menuju Desa Medahan kearah selatan kurang lebih 500 meter sampailah di Pura Masceti yang berhadapan dengan Pantai Masceti. Struktur Pura Masceti yang dapat dijabarkan melalui Palinggih dan Bangunan yang terdapat di Tri Mandala Pura Masceti. Menurut Purana Pura Mangening, Pura Masceti berfungsi untuk memuja Dewi Danu sebagai Dewi Kesuburan (Dewi Sri) yakni dewa yang menguasai pertanian dan untuk memuja Dewa Baruna sebagai dewa sumber amerta (kesuburan) Dewa yang menguasai laut. Sebagaimana mestinya bahwa pencetus Pura Masceti merupakan Subak, yakni warga dari Subak Pakerisan Teben dan Gunung Sari sehingga Pura Masceti digolongkan sebagai Pura yang berstatus sebagai Pura Fungsional
(Swagina). Selain itu Pura Masceti juga merupakan termasuk dalam kategori Pura Kahyangan Jagat.

\subsection{Potensi Wisata yang bersifat alami}

Kawasan Suci Pura Masceti berlokasi di pinggir Pantai yang juga bernama Pantai Masceti. Sehingga Potensi Wisata Alam yang ada di Kawasan Suci Pura Masceti adalah Pantai Masceti. Lokasi Pantai Masceti yang berdekatan dengan Pura Masceti membuat Pantai ini menjadi disakralkan atau disucikan.

\subsection{Potensi Wisata yang bersifat sosial kebudayaan \\ Pura Masceti yang merupakan Pura yang} berstatus Kahyangan Jagad di pulau Bali yang dipelopori oleh Subak. Sehingga Pura Masceti memiliki potensi wisata yang mencirikan sosial dan kebudayaan. Arsitektur Pura Masceti yang masih kental dan unik yang menjadikan Pura Masceti ini memiliki daya tarik tersendiri terhadap wisatawan. Selain Pura Masceti yang merupakan potensi utama dari Kawasan Suci Pura Masceti terdapat bangunan baru di sebelah utara Pura Masceti atau tepatnya jalan utama masuk ke Jaba Sisi Pura Masceti. Bangunan ini merupakan bangunan yang diperuntukan sebagai Museum yaitu Museum Subak.

\subsection{Potensi Wisata yang bersifat buatan}

Terdapat sebuah bangunan yang cukup berumur di bagian sebelah barat Kawasan Suci Pura Masceti yang berhadapan dengan pantai. Gedung yang sudah berdiri kurang lebih 37 tahun yang lalu ini merupakan milik pribadi yaitu I Ketut Sugata. Berdasarkan informasi dari beliau awal pembangunan Gedung Angsa ini adalah untuk tempat pemandian atau sebagai kolam renang. Makna filosofis menurut beliau mengenai struktur bangunan yang menyerupai angsa ini adalah Angsa memiliki makna kebijaksanaan, sederhana, sabar dan tidak menyakiti binatang yang lain. Berada di lumpur dan memilih sari patih tanah sebagai makanannya inti sari tanah itulah yang merupakan nilai luhur. 


\subsection{Persepsi Wisatawan terhadap atraksi wisata \\ Tabel 4.4.1 Korelasi dan reliabilitas Indikator Atraksi Wisata}

\begin{tabular}{|ll|r|r|r|r|}
\hline \multicolumn{5}{c}{ Correlations } \\
\hline X1.1 & \multicolumn{1}{c|}{ X1.1 } & Drop Out & \multicolumn{1}{c|}{ X1.3 } & \multicolumn{1}{c|}{ X1 } \\
& Pearson Correlation & 1 & .292 & $.437^{*}$ & $.701^{* *}$ \\
& Sig. (2-tailed) & & .117 & .016 & .000 \\
& $\mathrm{~N}$ & 30 & 30 & 30 & 30 \\
\hline \multirow{2}{*}{ Drop Out } & Pearson Correlation & .292 & 1 & .081 & .057 \\
& Sig. (2-tailed) & 117 & & .670 & .765 \\
& $\mathrm{~N}$ & 30 & 30 & 30 & 30 \\
\hline \multirow{2}{*}{ X1.3 } & Pearson Correlation & $.437^{*}$ & -.081 & 1 & $.653^{* *}$ \\
& Sig. (2-tailed) & .016 & .670 & & .000 \\
& $\mathrm{~N}$ & 30 & 30 & 30 & 30 \\
\hline \multirow{2}{*}{ X1 } & Pearson Correlation & $.701^{* *}$ & .057 & $.653^{* *}$ & 1 \\
& Sig. (2-tailed) & .000 & .765 & .000 & \\
& $\mathrm{~N}$ & 30 & 30 & 30 & 30 \\
\hline
\end{tabular}

\begin{tabular}{|c|c|c|c|}
\hline \multicolumn{4}{|c|}{ Case Processing Summary } \\
\hline & & $\mathrm{N}$ & $\%$ \\
\hline \multirow[t]{3}{*}{ Cases } & Valid & 30 & 100.0 \\
\hline & Excluded $^{\mathrm{a}}$ & 0 & .0 \\
\hline & Total & 30 & 100.0 \\
\hline
\end{tabular}

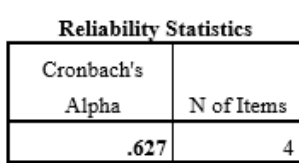

Sumber : Hasil Analisis Data Primer (2017)

Tabel 4.4.1 menjelaskan bahwa indikator pernyataan X1.1 memiliki nilai korelasi 0,701 dan indikator pernyataan X1.3 memiliki nilai korelasi 0,652. Berdasarkan nilai tersebut, dapat diketahui bahwa indikator pernyataan variabel Lokasi Kawasan Suci X1.1 dan X1.3 pada penelitian ini dapat dinyatakan valid. Sedangkan X1.2 tidak memenuhi syarat validitas yaitu lebih besar dari 0,30 sehingga data tersebut termasuk dalam kategori drop out. Indikator Pernyataan dari tabel 4.4.1 di atas dapat diketahui bahwa variabel Persepsi Wisatawan terhadap Atraksi Wisata X1.1 dan X1.3 pada penelitian ini dapat dinyatakan reliabel. Hal ini terlihat pada nilai Cronbach's Alpha yaitu 0,627 yang berarti melebihi angka minimum 0,60 .

Tabel 4.4.2 Analisis Frekuensi Persepsi wisatawan terhadap Atraksi Wisata

\begin{tabular}{|c|c|c|c|c|c|c|}
\hline \multirow{2}{*}{ No. } & \multirow{2}{*}{ Pernyataan } & \multicolumn{5}{|c|}{ Jawaban } \\
\hline & & STS & TS & BS & $\mathrm{S}$ & SS \\
\hline 1 & $\begin{array}{lr}\text { Pantai } & \text { Masceti } \\
\text { merupakan } & \text { pantai } \\
\text { yang indah } & \end{array}$ & $\begin{array}{c}0.0 \\
\%\end{array}$ & $\begin{array}{c}0.0 \\
\%\end{array}$ & $\begin{array}{l}26 . \\
7 \%\end{array}$ & $\begin{array}{l}63 . \\
3 \%\end{array}$ & $\begin{array}{c}10.0 \\
\%\end{array}$ \\
\hline$z$ & $\begin{array}{l}\text { Museum Subak } \\
\text { yang berada di } \\
\text { Kawasan Suci Pura } \\
\text { Masceti membuat } \\
\text { anda tertarik untuk } \\
\text { berkunjung }\end{array}$ & $\begin{array}{c}0.0 \\
\%\end{array}$ & $\begin{array}{l}20 . \\
0 \%\end{array}$ & $\begin{array}{l}20 . \\
0 \%\end{array}$ & $\begin{array}{l}46 \\
7 \%\end{array}$ & $\begin{array}{c}33.3 \\
\%\end{array}$ \\
\hline
\end{tabular}

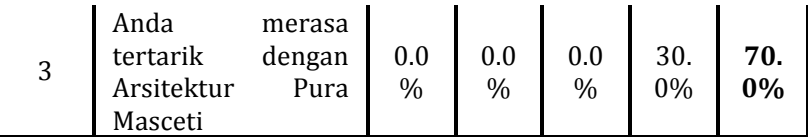

Sumber : Hasil Analisis Data Primer (2017)

Tabel 4.4.2 menjelaskan bahwa pendapat wisatawan dari indikator pernyataan Persepsi Wisatawan terhadap Atraksi Wisata (X1) yaitu X1.1 didominasi oleh jawaban Setuju dengan nilai $63.3 \%$, jawaban dan indikator pernyataan X1.3 mendapatkan nilai 70\% yang didominasi dengan jawaban Sangat Setuju. Sehingga sebagian besar wisatawan menyetujui bahwa mereka merasa tertarik terhadap Arsitektur Pura Masceti.

\subsection{Persepsi Wisatawan terhadap akses} menuju lokasi

Tabel 4.5.1 Korelasi dan reliabilitas Indikator Akses Menuju Lokasi

\begin{tabular}{|ll|r|r|r|}
\hline \multicolumn{4}{c|}{ Correlations } \\
\hline & & \multicolumn{1}{c|}{ X2.4 } & \multicolumn{1}{c|}{ X2.5 } & \multicolumn{1}{c|}{ X2 } \\
\hline X2.4 & Pearson Correlation & 1 & $.420^{*}$ & $.831^{*+}$ \\
& Sig. (2-tailed) & & .021 & .000 \\
& $\mathrm{~N}$ & 30 & 30 & 30 \\
\hline $\mathrm{X} 2.5$ & Pearson Correlation & $.420^{\circ}$ & 1 & $.854^{*+}$ \\
& Sig. (2-tailed) & .021 & & .000 \\
& $\mathrm{~N}$ & 30 & 30 & 30 \\
\hline $\mathrm{X} 2$ & Pearson Correlation & $.831^{* *}$ & $.854^{* *}$ & 1 \\
& Sig. (2-tailed) & .000 & .000 & \\
& $\mathrm{~N}$ & 30 & 30 & 30 \\
\hline
\end{tabular}
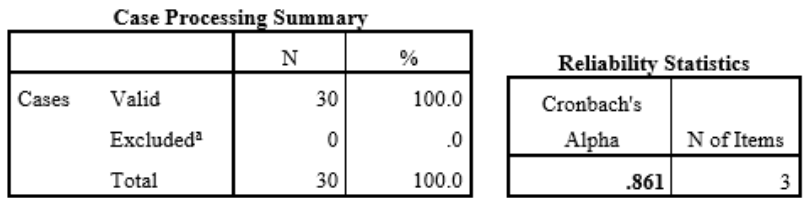

Sumber : Hasil Analisis Data Primer (2017)

Tabel 4.5.1 menjelaskan bahwa indikator pernyataan X2.4 memiliki nilai korelasi 0,831 dan indikator pernyataan X2.5 memiliki nilai korelasi 0,854. Berdasarkan nilai tersebut, dapat diketahui bahwa seluruh indikator pernyataan variabel Kebersihan Kawasan Suci X2.4 dan X2.5 pada penelitian ini dapat dinyatakan valid. Tabel 4.5.1 menjelaskan bahwa Indikator Pernyataan dari variabel Persepsi Wisatawan terhadap Akses Menuju Lokasi X2.4 dan X2.5 pada penelitian ini dapat dinyatakan reliabel. Hal ini terlihat pada nilai Cronbach's Alpha yaitu 0,861 yang berarti melebihi angka minimum 0,60. Maka 
pernyataan dari indikator dalam penelitian ini dapat digunakan.

Tabel 4.5.2 Analisis Frekuensi Persepsi wisatawan terhadap Akses Menuju Lokasi

\begin{tabular}{|c|l|c|c|c|c|c|}
\hline \multirow{2}{*}{ No. } & \multicolumn{1}{|c|}{ Pernyataan } & \multicolumn{5}{|c|}{ Jawaban } \\
\cline { 3 - 7 } & & ST & TS & BS & S & SS \\
\hline \multirow{5}{*}{4} & Lokasi Kawasan Suci & & & & & \\
& $\begin{array}{l}\text { Pura Masceti sangat } \\
\text { strategis dengan }\end{array}$ & 0.0 & 20. & $\mathbf{5 0 .}$ & 30. & 0.0 \\
& destinasi yang lain & $\%$ & $0 \%$ & $\mathbf{0 \%}$ & $0 \%$ & $\%$ \\
& dan pusat kota & & & & & \\
\hline \multirow{2}{*}{5} & Akses menuju lokasi & 0.0 & 0.0 & 40. & 40. & 20.0 \\
& sangat memadai & $\%$ & $\%$ & $0 \%$ & $0 \%$ & $\%$ \\
\hline
\end{tabular}

Sumber : Hasil Analisis Data Primer (2017)

Pada tabel 4.5.2 menjelaskan bahwa jawaban pada indikator pernyataan Persepsi Wisawatawan terhadap Akses Menuju Lokasi (X2) yaitu X2.4 didominasi oleh jawaban Biasa Saja dengan nilai $50 \%$ dan jawaban pada indikator pernyataan X2.5 memiliki nilai yang seimbang antara Biasa Saja dan Setuju dengan nilai $40 \%$. Sehingga sebagian besar wisatawan memberikan respon yang biasa - biasa saja terhadap akses yang ada di Kawasan Suci Pura Masceti, menurut mereka akses ke kawasan tersebut belum cukup strategis dengan destinasi-destinasi yang lain. Selain itu, wisatawan berpendapat bahwa akses menuju lokasi yang ditandai dengan frekuensi yang seimbang antara Biasa Saja dan Setuju. Diperkuat dengan tambahan poin $20 \%$ menyatakan setuju bahwa Akses Menuju Lokasi memadai.

\subsection{Persepsi Wisatawan terhadap sarana pariwisata \\ Tabel 4.6.1 Korelasi dan reliabilitas Indikator Sarana Pariwisata}

\begin{tabular}{|c|c|c|c|c|c|}
\hline \multicolumn{6}{|c|}{ Correlations } \\
\hline & & Drop Out & $\mathrm{X} 3.7$ & $\mathrm{X} 3.8$ & $\mathrm{X} 3$ \\
\hline \multirow[t]{3}{*}{ Drop Out } & Pearson Correlation & 4 & $-416^{*}$ & 157 & 213 \\
\hline & Sig. (2-tailed) & & .022 & .407 & 259 \\
\hline & $\mathrm{N}$ & 30 & 30 & 30 & 30 \\
\hline \multirow[t]{3}{*}{$\mathrm{X} 3.7$} & Pearson Correlation & $.416^{\circ}$ & 1 & .059 & $.637^{\star *}$ \\
\hline & Sig. (2-tailed) & .022 & & .757 & .000 \\
\hline & $\mathrm{N}$ & 30 & 30 & 30 & 30 \\
\hline \multirow[t]{3}{*}{$\mathrm{X} 3.8$} & Pearson Correlation & -.157 & .059 & 1 & $.467^{\text {t* }}$ \\
\hline & Sig. (2-tailed) & .407 & .757 & & .009 \\
\hline & $\mathrm{N}$ & 30 & 30 & 30 & 30 \\
\hline \multirow[t]{3}{*}{$\mathrm{x} 3$} & Pearson Correlation & .213 & $.637^{* *}$ & $.467^{* *}$ & 1 \\
\hline & Sig. (2-tailed) & .259 & .000 & .009 & \\
\hline & $\mathrm{N}$ & 30 & 30 & 30 & 30 \\
\hline
\end{tabular}

\begin{tabular}{|c|c|c|c|}
\hline \multicolumn{4}{|c|}{ Case Processing Summary } \\
\hline & & $\mathrm{N}$ & $\%$ \\
\hline \multirow[t]{3}{*}{ Cases } & Valid & 30 & 100.0 \\
\hline & Excluded $^{\mathrm{a}}$ & 0 & .0 \\
\hline & Total & 30 & 100.0 \\
\hline
\end{tabular}

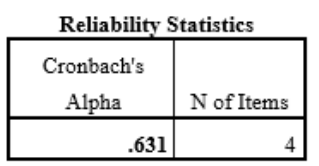

Sumber : Hasil Analisis Data Primer (2017)

Tabel 4.6.1 menjelaskan bahwa indikator pernyataan X3.7 memiliki nilai korelasi 0,637 dan indikator pernyataan X3.8 memiliki nilai korelasi 0,467. Berdasarkan nilai tersebut, dapat diketahui bahwa indikator pernyataan variabel Sarana Pariwisata X3.7 dan X3.8 pada penelitian ini dapat dinyatakan valid. Sedangkan X3.6 tidak memenuhi syarat validitas yaitu lebih besar dari 0,30 sehingga data tersebut termasuk dalam kategori drop out. Tabel 4.6.1 menjelaskan bahwa Indikator Pernyataan dari variabel Persepsi Wisatawan terhadap Sarana Pariwisata X3.7 dan X3.8 pada penelitian ini dapat dinyatakan reliabel. Hal ini terlihat pada nilai Cronbach's Alpha yaitu 0,631 yang berarti melebihi angka minimum 0,60. Maka pernyataan dari indikator dalam penelitian ini dapat digunakan. 
Tabel 4.6.2 Analisis Frekuensi Persepsi wisatawan terhadap Sarana Pariwisata

\begin{tabular}{|c|c|c|c|c|c|c|}
\hline \multirow{2}{*}{ No. } & \multirow{2}{*}{ Pernyataan } & \multicolumn{5}{|c|}{ Jawaban } \\
\hline & & STS & TS & BS & S & SS \\
\hline 6 & $\begin{array}{l}\text { Kawasan Suci Pura } \\
\text { Masceti-sudah } \\
\text { memiliki sarana } \\
\text { pariwisata } \\
\text { penginapan yang } \\
\text { memadai yang tak } \\
\text { jauh-dari Kawasan } \\
\text { SuciPura Masceti }\end{array}$ & $\begin{array}{l}\theta .0 \\
\%\end{array}$ & $\begin{array}{l}0.0 \\
\%\end{array}$ & $\begin{array}{c}\theta .0 \\
\%\end{array}$ & $\begin{array}{l}36 . \\
7 \%\end{array}$ & $\begin{array}{l}63 \\
3 \%\end{array}$ \\
\hline 7 & $\begin{array}{lr}\text { Kawasan Suci Pura } \\
\text { Masceti } & \text { sudah } \\
\text { memiliki } & \text { fasilitas } \\
\text { umum r seperti } \\
\text { toilet, warung dan } \\
\text { parkir } \\
\text { memadai }\end{array}$ & $\begin{array}{c}0.0 \\
\%\end{array}$ & $\begin{array}{l}20 . \\
0 \%\end{array}$ & $\begin{array}{l}63 . \\
3 \%\end{array}$ & $\begin{array}{l}16 . \\
7 \%\end{array}$ & $\begin{array}{c}0.0 \\
\%\end{array}$ \\
\hline 8 & $\begin{array}{lr}\text { Pantai } & \text { Masceti } \\
\text { sudah } & \text { memenuhi } \\
\text { kriteria } & \text { sebagai } \\
\text { sebuah } & \text { destinasi } \\
\text { dengan } & \text { segala } \\
\text { fasilitas umumnya }\end{array}$ & $\begin{array}{c}0.0 \\
\%\end{array}$ & $\begin{array}{c}0.0 \\
\%\end{array}$ & $\begin{array}{c}0.0 \\
\%\end{array}$ & $\begin{array}{l}46 . \\
7 \%\end{array}$ & $\begin{array}{l}53 . \\
3 \%\end{array}$ \\
\hline
\end{tabular}

Sumber : Hasil Analisis Data Primer (2017)

Tabel 4.6.2 menjelaskan bahwa jawaban pada indikator pernyataan Sarana Pariwisata (X3) yaitu X3.7 didominasi oleh jawaban Biasa Saja dengan nilai $63.3 \%$ dan pada indikator X3.8 didominasi oleh jawaban Sangat Setuju dengan nilai 53.3\%. Sehingga sebagian besar wisatawan memberikan respon yang biasa biasa saja terhadap Sarana Pariwisata yang memadai di Kawasan Suci Pura Masceti. Beberapa fasilitas telah dibangun dan beberapa fasilitas masih dalam proses pembangunan. Selain itu lahan parker di Kawasan Suci Pura Masceti sangat luas namun belum rapi sehingga perlu adanya penataan. Indikator berikutnya wisatawan memberikan tanggapan Sangat Setuju terhadap kriteria sebuah destinasi dengan segala fasilitas umum Pantai Masceti.

\subsection{Persepsi Wisatawan terhadap kualitas pelayanan \\ Tabel 4.7.1 Korelasi dan reliabilitas Indikator Kualitas pelayanan}

\begin{tabular}{|ll|r|r|r|r|r|}
\hline \multicolumn{7}{|c|}{ Correlations } \\
\hline & \multicolumn{1}{c|}{ Y.9 } & \multicolumn{1}{c|}{ Y.10 } & \multicolumn{1}{c|}{ Y.11 } & \multicolumn{1}{c|}{ Y.12 } & \multicolumn{1}{c|}{ Y } \\
\hline Y.9 & Pearson Correlation & 1 & .173 & $.388^{*}$ & .015 & $.385^{*}$ \\
& Sig. (2-tailed) & & .361 & .034 & .938 & .036 \\
N & 30 & 30 & 30 & 30 & 30 \\
\hline Y.10 Pearson Correlation & .173 & 1 & .207 & $.400^{*}$ & $.394^{*}$ \\
& Sig. (2-tailed) & .361 & & .272 & .029 & .031 \\
N & 30 & 30 & 30 & 30 & 30 \\
\hline Y.11 Pearson Correlation & $.388^{*}$ & .207 & 1 & .357 & $.741^{* *}$ \\
& Sig. (2-tailed) & .034 & .272 & & .053 & .000 \\
N & 30 & 30 & 30 & 30 & 30 \\
\hline Y.12 Pearson Correlation & .015 & $.400^{*}$ & .357 & 1 & $.612^{* *}$ \\
& Sig. (2-tailed) & .938 & .029 & .053 & & .000 \\
N & 30 & 30 & 30 & 30 & 30 \\
\hline Y & Pearson Correlation & $.385^{*}$ & $.394^{*}$ & $.741^{* *}$ & $.612^{* *}$ & 1 \\
Sig. (2-tailed) & .036 & .031 & .000 & .000 & \\
N & 30 & 30 & 30 & 30 & 30 \\
\hline
\end{tabular}

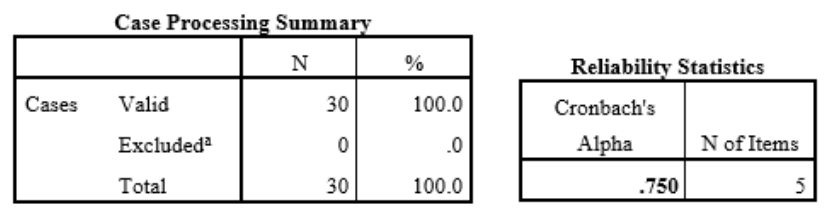

Sumber : Hasil Analisis Data Primer (2017)

Tabel 4.7.1 menjelaskan bahwa indikator pernyataan Y.9 memiliki nilai korelasi 0,385, indikator pernyataan Y.10 memiliki korelasi 0,394, indikator Y.11 memiliki korelasi 0,741 dan indikator pernyataan Y.12 memiliki nilai korelasi 0,612. Berdasarkan nilai tersebut, dapat diketahui bahwa seluruh indikator pernyataan variabel Kualitas Potensi Wisata Y.9-Y.12 pada penelitian ini dapat dinyatakan valid. Tabel 4.7 menjelaskan bahwa Indikator Pernyataan dari variabel Persepsi Wisatawan terhadap Kualitas Pelayanan Y.9-Y.12 pada penelitian ini dapat dinyatakan reliabel. Hal ini terlihat pada nilai Cronbach's Alpha yaitu 0,750 yang berarti melebihi angka minimum 0,60. Maka pernyataan dari indikator dalam penelitian ini dapat digunakan. 
Tabel 4.7.2 Analisis Frekuensi Persepsi wisatawan terhadap Kualitas pelayanan

\begin{tabular}{|c|c|c|c|c|c|c|}
\hline \multirow[b]{2}{*}{ No. } & \multirow{2}{*}{ Pernyataan } & \multicolumn{5}{|c|}{ Jawaban } \\
\hline & & $\begin{array}{c}\text { ST } \\
\text { S }\end{array}$ & TS & BS & $\mathrm{S}$ & SS \\
\hline 9 & $\begin{array}{l}\text { Anda sudah menjaga } \\
\text { kerbersihan Kawasan } \\
\text { Suci Pura Masceti }\end{array}$ & $\begin{array}{c}0.0 \\
\%\end{array}$ & $\begin{array}{c}6.7 \\
\%\end{array}$ & $\begin{array}{l}23 . \\
3 \%\end{array}$ & $\begin{array}{c}70 . \\
\mathbf{0} \%\end{array}$ & $\begin{array}{c}0.0 \\
\%\end{array}$ \\
\hline 10 & $\begin{array}{l}\text { Anda merasa tertarik } \\
\text { dengan Arsitektur Pura } \\
\text { Masceti }\end{array}$ & $\begin{array}{c}0.0 \\
\%\end{array}$ & $\begin{array}{c}0.0 \\
\%\end{array}$ & $\begin{array}{l}16 . \\
7 \%\end{array}$ & $\begin{array}{l}46 . \\
7 \%\end{array}$ & $\begin{array}{c}36.7 \\
\%\end{array}$ \\
\hline 11 & $\begin{array}{l}\text { Anda sudah merasa } \\
\text { nyaman dan aman saat } \\
\text { berkunjung ke lokasi }\end{array}$ & $\begin{array}{c}0.0 \\
\%\end{array}$ & $\begin{array}{l}16 . \\
7 \%\end{array}$ & $\begin{array}{c}50 . \\
0 \%\end{array}$ & $\begin{array}{l}33 \\
3 \%\end{array}$ & $\begin{array}{c}0.0 \\
\%\end{array}$ \\
\hline 12 & $\begin{array}{l}\text { Anda mendapatkan } \\
\text { kesan yang positif saat } \\
\text { kunjungan yang } \\
\text { membuat anda tertarik } \\
\text { untuk berkunjung } \\
\text { kembali }\end{array}$ & $\begin{array}{c}0.0 \\
\%\end{array}$ & $\begin{array}{c}0.0 \\
\%\end{array}$ & $\begin{array}{c}0.0 \\
\%\end{array}$ & $\begin{array}{l}53 . \\
3 \%\end{array}$ & $\begin{array}{c}46.7 \\
\%\end{array}$ \\
\hline
\end{tabular}

Sumber : Hasil Analisis Data Primer (2017)

Tabel 4.7.2 menjelaskan bahwa indikator pernyataan Persepsi Wisatawan terhadap Kualitas Pelayanan (Y) yaitu Y.9 didominasi oleh jawaban Setuju dengan nilai 70\%, pada indikator Y.10 juga didominasi oleh jawaban Setuju dengan nilai 46.7\%, pada indikator Y.11 didominasi oleh jawaban Biasa Saja dengan nilai 50\% dan pada indikator Y.12 didominasi oleh jawaban Setuju dengan nilai 53.3\%. Sehingga sebagian besar wisatawan menyetujui bahwa Pantai Masceti merupakan Pantai yang bersih. Wisatawan juga memberikan tanggapan yang positif mengenai pelayanan di Kawasan Suci Pura Masceti tersebut. Namun sebagain besar wisatawan memberikan tanggapan yang biasa-biasa saja terhadap perasaan aman dan nyaman saat berkunjung ke lokasi. Sebagian besar wisatawan mendapatkan kesan yang positif saat berkunjung dan tertarik untuk datang kembali

\section{PENUTUP}

\subsection{Simpulan}

Kawasan Suci Pura Masceti memiliki potensi - potensi wisata yang bersifat alami, sosial atau kebudayaan dan buatan. Potensi alami yang dimiliki di Kawasan Suci Pura Masceti adalah Pantai Masceti. Pantai Masceti memiliki daya tarik wisata sehingga Pantai Masceti kerap dijadikan tempat kegiatan Yoga. Potensi Sosial atau kebudayaan yang terdapat di Kawasan Suci Pura Masceti adalah Pura
Masceti dan Museum Subak. Pura Masceti memiliki daya tarik sehingga Pura Masceti kerap dijadikan tempat kegiatan Meditasi. Potensi Bisnis atau Ekonomi yang terdapat di Kawasan Suci Pura Masceti adalah Bangunan Angsa. Bangunan Angsa ini memiliki design yang sangat unik namun bangunan ini belum rampung.

Berdasarkan dari 30 kuesioner yang disebarkan ke wisatawan yang berkunjung ke Kawasan Suci Pura Masceti dan dianggap kredibel dalam menjawab telah melalui tahap uji kuesioner yaitu validitas dan reliabilitas menghasilkan analisis frekuensi persepsi wisatawan terhadap Variabel Kawasan Suci Pura Masceti. Indikator pernyataan X1.1 memperoleh respon Setuju dengan nilai $63.3 \%$, indikator pernyataan X1.3 memperoleh respon Sangat Setuju dengan nilai $70 \%$, indikator pernyataan X2.4 memperoleh respon Biasa Saja dengan nilai $50 \%$, indikator pernyataan X2.5 memperoleh respon yang seimbang antara Biasa Saja dan Setuju dengan nilai masing masing 40\%, indikator pernyataan X3.7 memperoleh respon Biasa Saja dengan nilai $63.3 \%$, indikator pernyataan X3.8 memperoleh respon Sangat Setuju dengan nilai 53.3\%, indikator pernyataan Y.9 memperoleh respon Setuju dengan nilai $70 \%$, indikator pernyataan Y.10 memperoleh respon Setuju dengan nilai $46.7 \%$, indikator pernyataan Y.11 memperoleh respon Biasa Saja dengan nilai $50 \%$ dan indikator pernyataan terakhir Y.12 memperoleh respon Setuju dengan nilai 53.3\%

\subsection{Saran}

Kawasan Suci Pura Masceti sudah memiliki potensi - potensi wisata yang bersifat alami, sosial atau kebudayaan dan buatan sehingga perlu adanya arah pengembangan potensi potensi yang akan diterapkan yang harus mengikuti aturan - aturan yang ada di Kawasan Suci Pura Masceti. Peran Pemerintah Kabupaten Gianyar sekiranya dapat melihat potensi - potensi wisata tersebut sehingga dapat memberikan dukungan dana dan menjadi fasilitator demi arah pengembangan Kawasan Suci Pura Masceti dapat terealisasikan tanpa mengurangi kesucian Pura Masceti sebagai Pura Kahyangan Jagat di Kabupaten Gianyar, Bali. 


\section{DAFTAR PUSTAKA}

Akdon, dan Riduwan, 2013. Rumus dan Data dalam Aplikasi Statistika, Bandung : Alfabeta.

Arikunto, S. 2002. Prosedur Suatu Penelitian: Pendekatan Praktek. Edisi Revisi. Kelima. Penerbit Rineka Cipta. Jakarta.

Ariyanto. 2005. Ekonomi Pariwisata. Jakarta: Penerbit Rineka Cipta.

Benny, dkk 2015. 'Perception of Tourist towards the Potential Development of Tumpa Mountain Area as Integrated Ecotourism, Manado, North Sulawesi Province'. Journal of Indonesian Tourism and Development Studies vol. 3.

Budiyono. 2003. Metodologi Penelitian Pendidikan. Surakarta: UNS Press.

Ghozali, Imam. 2011. Aplikasi Analisis Multivariate Dengan Program IBM. SPSS 19 (edisi kelima.) Semarang: Universitas Diponegoro.

Martono, Nanang. 2010. Metode Penelitian Kuantitatif Analisis Isi dan Analisis Data Sekunder, Jakarta : PT Raja Grafindo Persada.

Robbins, S.P. 2003. Perilaku Organisasi Jilid I. Jakarta: PT INDEKS Kelompok Garmedia.

Sugiyono, 2005. Memahami Penelitian Kualitatif. Bandung : Alfabeta.

Sujali. 1989. Geografi Pariwisata dan Kepariwisataan. Yogyakarta : UGM Press

Umar Husein. 2003. Metode Riset Komunikasi Oraganisasi Jakarta : PT Gramedia Pustaka Utama. 